\title{
Revisiting Children's Images of Literacy
}

\author{
by \\ Maureen E. Kendrick \\ University of British Columbia \\ and \\ Roberta A. McKay \\ University of Alberta
}

Children make metaphoric use of symbols that are available to them at any one time and endow these symbols with a variety of new meanings (Steedman, 1982). From a practical standpoint, this means that children bring their own interpretive framework and manner of appropriation to the various cultural materials to which they are exposed (Nicolopoulou, Scales, \& Weintraub, 1994). Our early research into images of literacy began with the basic question "Do children have visual images of literacy?" Over the past four years, we have collected over 270 drawings that represent children's constructions of reading and writing across the broad contexts of their lives (see e.g., McKay \& Kendrick, 1999, 2001a, 2001b). In the process, we not only discovered that children have very rich images of literacy, but that their drawings reveal complex understandings about the multi-faceted and interactive nature of literacy. Moreover, how children perceive themselves, and others, in relation to literacy is evident in their drawings.

In our previous studies, our examinations of the children's drawings resulted in a categorization scheme that included primary, secondary, and unknown images of literacy. Primary images included drawings in which literacy was the central topic of the drawing (e.g., a picture of someone reading books, writing stories and letters, or teaching the alphabet); secondary images included drawings where literacy artifacts or events were "add-on" components of the drawing (e.g., a drawing that is predominantly about dinosaurs that includes a small sketch of a book in the corner of the page), and unknown images which included drawings that did not appear to relate to reading and writing, in particular, or language learning, in general (e.g., drawings of sports equipment or animals). In reporting results, we focused mainly on children's primary and secondary images of literacy, discarding to a large extent those that we had identified as "unknown." In this paper, through the example of one boy's "unknown" image of literacy (a graphic drawing of a recently killed buck), we illustrate how a closer examination of the drawing from the child's perspective illuminated a more expansive and inclusive view of literacy than our initial categorization scheme revealed. We believe that the process we underwent as researchers reveals the importance of adopting multiple perspectives in understanding the complexity of children's constructions of literacy, gender, and identity.

\section{Children's Drawings as a Research Tool}

It has only been within the last three decades that qualitative researchers have given serious consideration to the use of images with words to enhance understanding of the human condition (Prosser, 1998). Image-based research includes moving forms such as films and videos, as well as still images such as photographs, drawings, graffiti, and cartoons. Prosser further asserts that images provide researchers with a different order of data and an alternative to the ways in which we have perceived data in the past. Specifically, he argues that image-based research is differently situated than other forms of research because visual images are different in nature from words in their allusion to reality and in the ways in which participants see themselves and can be seen by others. 
Children's drawings in particular have been referred to as "interesting mixes of graphic and linguistic resources, in the service of complex conceptualization" (Gardner, 1980, p. 154). In a similar vein, Weber and Mitchell (2000) suggest that drawings can communicate simultaneously on many levels as "layered paintings that hide or combine other social, cultural, and personal images" (p. 19). These authors, who used students' drawings of teachers to gain insights into how students read the cultural imagery of teaching, also underscore that aspects of personal and social knowledge that may have been overlooked in other sources may be more available in drawings. While image-based research has been utilized in a limited way within the field of education (see e.g., Haney, 1984; Lifford, Byron, Eckblad, \& Ziemian, 2000; Prosser, 1998) our focus on its use to understand children's knowledge of literacy is unique. Specifically, we use children's drawings of reading and writing to investigate their conceptualizations of literacy in order to inform us, as teachers and researchers, about literacy knowledge of individual children as well as groups of children.

\section{Accessing Children's Images of Literacy}

The current study included students in Grades 1 to $6(n=187)$. The school where the research was conducted is located in a middle socio-economic class neighborhood in a city in Western Canada. As in our previous studies, the procedure we followed in soliciting drawings included group discussions and individual interviews. Specifically, the participating students in each of the classrooms met in groups with both of the researchers for 60 minutes to discuss and draw pictures of their ideas about literacy in their lives in school, outside of school, and in the future. The groups ranged in size from four to twenty-one children, with the average group size being seventeen children. The participating children from each grade and the researchers met in the art room of the school. Because our goal was to explore children's images and ideas as evident in their drawings, the questions outlined below were used to guide the discussions rather than rigidly format them. The directions for the drawing task, as outlined in Question Six below, were deliberately left very open-ended and did not specify who or what should be in the drawing or where it might take place. The discussion provided the impetus for drawing and we were aware that hearing the ideas of their peers could influence what the children might draw.

1. What kind of reading/writing do you do in school/outside of school?

2. Why do you read/write in school/outside of school?

3. Where do you read/write in school/outside of school?

4. How is reading/writing in school both similar and different from reading/writing outside of school?

5. How do you think you will use reading/writing in the future, as you grow older?

6. Draw a picture of reading or writing. It can be a picture of reading or writing that you do at home or at school. It can be a picture of reading or writing that you do now or that you think you might do when you're older.

Following the discussion and drawing session, the students were asked to provide an explanation about their drawings. Older students wrote explanations, while younger students dictated to their teacher or one of the researchers. Each student was also interviewed individually. The explanations and interviews were used to verify the researchers' interpretations of the drawings (e.g., who and what was in the drawings, when and where the literacy event or activity took place, and why the child chose to draw what he or she did). In addition, each teacher was asked to rate each student who participated in the drawing as high, middle or low in relation to a general level of achievement in language arts. As described earlier, the drawings were then categorized as primary, secondary, or unknown images of literacy.

In examining the 32 drawings in the Grade 5 collection, we noticed a striking shift in how some of the boys in 
particular represented literacy. Specifically, although all of the students in Grades 1 to 4 had drawn images of literacy that were coded as primary or secondary, four of the boys in Grade 5 produced drawings that we categorized as unknown images of literacy (i.e., their drawings had no readily apparent connection to literacy). Three of these boys drew sports equipment: one drew a baseball, one drew a football, and one drew a hockey stick. The image produced by the fourth boy, Dustin, appears below. His drawing, which portrays a recently killed buck, attracted considerable attention from his peers and us in the process.

In-depth reading/writing interviews were conducted with all four boys individually to determine their interests, attitudes, knowledge about reading and writing (e.g., functions of reading and writing, reading/writing strategies, etc.), and self-appraisal (Bainbridge \& Malicky, 2000). Because Dustin's drawing was significantly different than the other three drawings, we choose to focus particularly on his interview, and have only conducted preliminary analysis of the interview data for the other boys. Interviews were also conducted with the Grade 5 classroom teachers about their language arts programmes. Our interview with Dustin revealed in a powerful and poignant way, how critical it is for researchers and teachers to carefully examine the information they collect their children's own lenses. Dustin's perspective was instrumental in moving us beyond a surface and singular interpretation of his drawing as something unrelated to literacy to the possibilities of multiple interpretations.

Dustin: An Illustrative Example

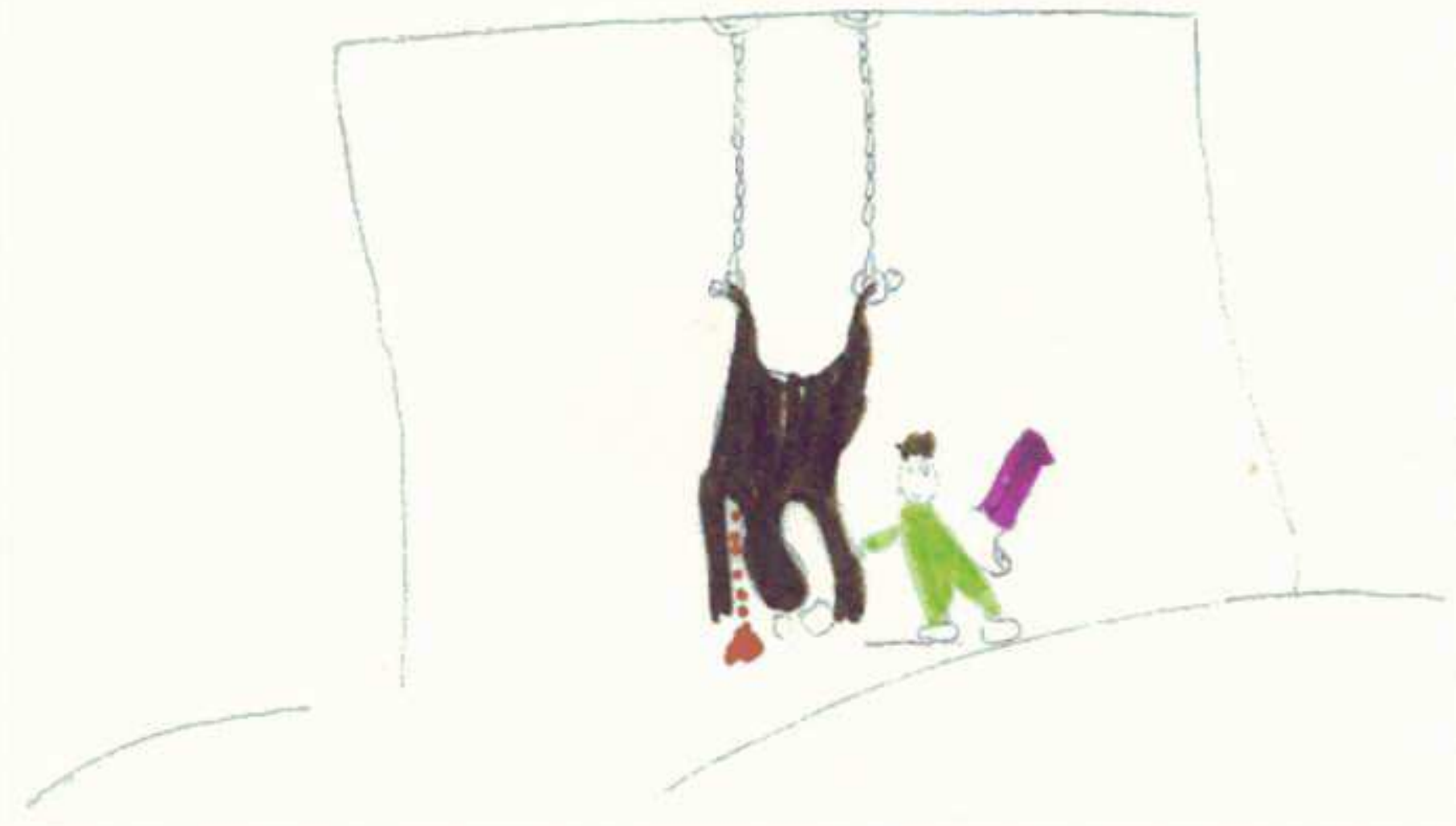

I shot my first buck with a doble barel shotgut.

It is at my grapernts farm. My dad Helped me.

(Dustin, Grade 5)

Dustin was an obvious leader among his male counterparts. During the discussion segment of our data collection, he was somewhat subdued, offering only the odd quip to secure his peers' attention. He was quick to begin drawing, though, and during the 60 minute period, completed two drawings. The first drawing, which was of a gopher being shot, was produced with considerable secrecy and shown only to a select few boys, 
who made comments in hushed tones. Dustin eventually crumpled this drawing into a ball, obscuring it from our view. The second attempt was preceded by cryptic queries such as: "Can we draw anything we want about reading and writing?" and "Does our teacher get to see it?" Once reassured that he was free to draw what he chose, and that his teacher would not see the drawing without his permission, he set to work with quiet determination.

It was obvious from Dustin's secrecy that guns and hunting were not topics that he thought would meet with his language arts teacher's approval; they were topics that, according to him, constituted "violence," something he said he was "not allowed to write about." Although our interview with Dustin's teacher did not confirm that she categorized hunting as violence, it was evident that guns, blood, and dismemberment were banned from classroom drawing, writing, and reading as part of the school's "zero tolerance" policy on violence. What is more important, perhaps, is Dustin's interpretation of this policy.

\section{Shifting Perspectives}

During the in-depth reading/writing interview, Dustin was articulate and talked at length about his interests, many of which focused on out of school activities. Among favorite pastimes, he listed "playing hockey, rollerblading, and basketball." "Gym" was identified as his preferred subject in school "because it's the most fun." When asked about what he liked to read and write, Dustin expressed a partiality for action. "Sometimes I read books," he explained, "it depends if I want to learn more about something. Like, I'd probably read about hockey." Additional reading interests included Harry Potter and "a book about the fur trade and Samuel D. Champlain's Indians and stuff." Dustin explained that he would rather watch a story on television than read it because "instead of just reading about it you can see the action while you're watching and you can hear exactly what they're saying and stuff."

Despite his inclination to watch television, Dustin indicated that he spends up to two hours reading at home everyday, though he confessed that most of his reading was homework related. In addition, he indicated that he occasionally read his own books at home, though he was unsure how many books he owned. On occasion, books were borrowed from the public library. When asked how he felt about reading, Dustin responded, "The stuff I like is pretty good. But sometimes, instead of just reading a book, I take the dictionary out and try to find stuff." He was somewhat less enthusiastic about writing, and explained, "I like writing some stuff 'cause last year I wanted to make up my own little stories, but then I wrote two chapters of it then I never had enough time."

Rowe and Harste (1986) emphasize that young readers and writers often demonstrate metalinguistic awareness that includes not only knowledge about language structures, but also "beliefs about oneself and others as language users, knowledge about the demands of different literacy events, a repertoires of language strategies, and knowledge about orchestrating this complex of concepts and strategies in the face of particular literacy events" (p. 236). Dustin, who had been ranked as average in achievement in language arts, demonstrated a keen awareness of his own literacy processes. In fact, it was the perception he revealed in his detailed discussion of his writing experiences at school that illuminated other possibilities for interpreting his drawing:

M: What about when you write? What do you think about?

D: When I write, I sometimes think about if I could write and then what I would write. Like, I think about what I wanna write if I can.

M: Do you mean it's hard for you to get your ideas down on paper?

D: Yeah, cause I'm thinking about something else that I wanna put down but we're not allowed. 
M: Can you tell me more about that?

D: Like, sometimes when she [the teacher], say she writes, "What did you do on the weekend?" I wanna write like I was shooting gophers or something like that. We're not allowed to write about anything with violence.

M: So, if you were allowed to write about those kinds of topics, how would that help you as a writer?

D: I would probably get better marks.

M: Yeah? Because you'd be writing about things that you're interested in?

D: Yeah, things I'm interested in and stuff I know about.

M: When you first drew your picture, you drew a gopher before, right? What were you thinking about when you drew that picture?

D: Sometimes I write about what I want to do in the future and stuff, and I think about that and I draw and write about what I did already. Like it might be something that happened four years ago. I draw about that if I remember it and it was good.

M: So when you're asked to write about things in school, do you sometimes find it hard to write about what the teacher asks you to write about?

D: Yeah, she just wants us to write about sunny days and stuff like that.

\section{The Need for Multiple Perspectives}

Dustin's reference to writing about "sunny days and stuff like that" smacks of what Barton (1994) refers to as schooled literacy, that is, the sanitized literacy activities that are characterized by the conventional types of processes and products typically found in schools. O'Brien (1998) argues that as students approach adolescence, "their experiences with reading materials and practices in school have taught them to dislike schooled literacy" (p. 29). Moreover, he points out that schooled literacy has been viewed as a means of technical control that enables teachers to determine the dispensation of curriculum content. Predictably, this technical control often restricts how students articulate their literacy. Dustin's candid portrayal of his school reading and writing experiences challenged our own assumptions about literacy and how students conceptualize it. Coming to understand how this drawing was embedded within the context of Dustin's life, both inside and outside of school, revealed the complexity of the image and the possibility of interpreting it as a representation of the multiple literacies that transcend school-based literacy and shape social identities (Alvermann, 1998). Dustin's "unknown" image of literacy when opened to multiple interpretations, suddenly offered rich possibilities as a source of information about literacy, identity and gender.

\section{An Act of Resistance}

Dustin's social status among his male peers, and the covertness with which he completed the drawing assignment, alerted us to the possibility that his drawing might represent an act of resistance to school. In particular, we considered that the drawing may constitute a small act of rebellion against the school's and his teacher's policy prohibiting violence as a topic of reading and writing. Goffman refers to this resistance as an "underlife," an attempt by an individual to "keep some distance, some elbow room, between himself and that with which others assume he should be identified" (1961, p. 319). Resistance of this nature may be especially attractive to boys who see "good studenthood" as "acquiescent, unmasculine, a denial of who they are and want to be" (Newkirk, 2000, p. 299). Indeed, many boys attempt to distance themselves from the "school" 
behaviors and language practices they perceive as threatening and feminine while trying to maintain their status as sons and peers. It is therefore a possibility that Dustin's drawing of the buck he shot is an act of resistance against a school-related assignment because it allowed him to position himself as a rebel among his peers. His two drawings, in fact, became playground legend and within a few days, we had a small entourage of younger students inquiring, "Did Dustin really draw a gopher with his head being shot off?" and "Did Dustin draw a buck with blood dripping from its head?"

\section{Preferred Writing Topics}

Given that Dustin clearly expressed a strong interest in writing about his hunting activities, we considered that the drawing might also represent topics about which he would like to write, but was not allowed to because, in his words, "[the teacher] just wants us to write about sunny days and stuff like that." As Schneider (2001) perceptively points out, "writing is about voices, thoughts, ideas, and experiences of real and sometimes 'messy' people" (p. 424); people who may make teachers feel uncomfortable for one reason or another. We live in a world that is redolent with topics (and people) we may not want children to think about, but children do think about these topics because they live them, and consequently, they may choose to write about topics such as violence, sexuality, racism, and the like (Schneider, 2001). Calkins (1994) argues that teachers often "invite children to bring their lives into the classroom" (1994, p. 17), but when students do actually bring their lives into their writing, they are frequently met with resistance. Teachers' levels of discomfort with particular topics, coupled with their positions of power in classrooms, allow them to question student voices in writing, which can often become a way of controlling the nature of free-writing in the classroom (Schneider, 2001).

What is the cost of controlling student writing? Solsken (1993) underscores that studies about how children learn literacy cannot be addressed without taking into account that "each and every literacy transaction is a moment of self-definition in which people take action within and upon their relations with other people. From this perspective, literacy learning would rarely be expected to proceed smoothly or without tension" (1993, p. 8). Language theorists such as Street (1995) and Gee (1989) have also made us aware that language is never neutral, but, rather, reflects particular ways of thinking, acting, interacting, and knowing. Giroux (1983) similarly locates literacy within a theoretical framework in which literacy is not merely considered as a technique, but rather a constitutive process of constructing meaning and critically interrogating the forces that shape lived experiences. In Solsken's words:

...In learning to read and write, children make choices through which they construct definitions of themselves and their relations with parents, siblings, teachers, and peers. In their choices, children, like adults, strive both to be counted as members of social groups and to be recognized as unique individuals. They seek to realize their culturally constructed intentions by acting on the material and social world. $(1993$, p. 9)

Literacy, in other words, constitutes the ways in which children orient themselves toward written language and its use. Because this orientation positions individuals and groups within hierarchies of social relations, children must learn to negotiate their literacy learning within various relations of power and status (Solsken, 1993). One location in which children confront these relations of power and status is in classroom contexts; it is within these contexts that spaces to explore multiple literacies are often limited or non-existent. Dustin's drawing may be viewed as part of the way in which he was negotiating his literacy learning within the hierarchical structures within his classroom and school.

\section{A Fond Memory}

From the interview transcript, we also considered that Dustin's drawing might illustrate a fond memory of hunting with his grandfather and father, an activity that constituted what he interpreted as a banned writing topic at school. As Newkirk (2000) claims, male students often perceive school-defined literacy as excluding-or even dismissing-their own narrative preferences. He also suggests that the appearance of "violence" in boys' writing may help form social bonds, and strongly emphasizes that it is essential to "read 
the subtext of the message." By extension, we wondered if Dustin might not imply some censure of the activities through which his male family members maintain their relationships. Clearly, to create equity in access to literacy, teachers will need to acknowledge the cultural materials (e.g., affection for parody, action, interest in sports, cartoons, video games) that certain students bring to the classroom. "Banning" or "modifying" these topics and materials is a form of cultural suppression that as a practice is sure to alienate both boys and girls from literacy and school culture in general (Newkirk, 2000).

Although teachers attempt to listen to the voices of students in their classrooms, they often exclude the "rich and nuanced literate lives they [lead] outside of...school-sanctioned literacy" (Phelps, 1998, p. 1). Fernie, Davies, Kantor, and McMurray (1993) suggest that students' positionings in classroom contexts represent complex interactions that include relationships of power, race, class, gender, and peer and student status. "Positionings" refer to possible ways of being and to each person's experience of those possibilities, as they are made available through specific discourses and contexts (Fernie et al., 1993). In learning literacy, children come to understand how to position themselves as people with recognizable social identities. Gilbert points out that it is partly in response to the social and cultural stories we hear and participate in that "we learn how to 'be' women or men, girls or boys, mothers or fathers, wives or husbands, sisters or brothers, aunts or uncles, grandmas or grandpas" (1994, p. 131). The full range of possibilities for students to explore their own social identities requires a much more dynamic and sophisticated approach than what is typically encompassed through school-sanctioned literacy (Phelps, 1998). Adopting Moll's (2000) concept of funds of knowledge, which recognizes the value of the cultural material all children bring to school and its importance in the development of literacy, provides a highly useful way in which to rethink the sanctioning of certain reading and writing topics over others.

\section{Conclusions}

It would have been easy for us as researchers to overlook Dustin's drawing or attribute its content to low achievement or disinterest in reading and writing. By revisiting Dustin's drawing, as he interpreted it for us within the context of his life both inside and outside the classroom, we were able tap into Dustin's own perception of the multiple literacies embedded in his drawing. The drawing provides a window on the complexities of literacy in students' lives and highlights the problems inherent in surface and singular interpretations of drawings, and reading and writing topics, thereby underscoring the need for multiple lensesparticularly children's own lenses-to explore alternative interpretations. We argue for the necessity of teachers, parents, and researchers to recognize that the construct of literacy is multidimensional and inextricably embedded within and diffused across the many contexts that constitute the wider social world of the classroom and beyond. Such a view, we assert, allows us to better see the accomplishments and struggles of individual children. We cannot assume the validity of discrete categories, roles, and labels because doing so constrains how we view and therefore understand children (Fernie et al., 1993). Using multiple lenses to interpret Dustin's drawing illuminates the cultural material embedded in the subtext of his drawing and provides insights into the complexities of how he positions himself as a social being. By failing to acknowledge the multiple ways in which students position themselves in relation to school literacy, we risk negating and silencing many students.

\section{References}

Alvermann, D. (1998). Imagining the possibilities. In Alvermann, D., Hinchman, K., Moore, D., Phelps, S, \& Waff, D. (Eds). Reconceptualizing the literacies in adolescents' lives (pp. 353-372). Mahwah, NJ: Lawrence Erlbaum Associates.

Bainbridge, J., \& Malicky, G. (2000). Constructing meaning: Balancing elementary language arts. Toronto: Harcourt Canada.

Barton, D. (1994). Literacy: An introduction to the ecology of written language. Cambridge, MA: Blackwell. 
Calkins, L. (1994). The art of teaching writing. Portsmouth, NH: Heinemann.

Davies, B. (1989). The discursive production of the male/female dualism in school settings. Oxford Review of Education, 15, 229-241.

Dyson, A. H. (1997). Writing superheroes: Contemporary childhood, popular culture, and classroom literacy. New York: Teachers College Press.

Fernie, D. E., Davies, B., Kantor, R., \& McMurray, P. (1993). Becoming a person in the preschool: creating integrated gender, school culture, and peer culture positionings. Qualitative Studies in Education, 6 (2), 95-110.

Gardner, H. (1980). Artful scribbles: The significance of children's drawings. New York: Basic Books.

Gee, J. P. (1989). Literacy, discourse, and linguistics: Introduction. Journal of Education, 171 (1), 5-17.

Gilbert, P. (1994). And they lived happily ever after. In A. Haas Dyson \& C. Genishi (Eds.), The need for story: Cultural diversity in classroom and community (pp. 124-142). Urbana, Illinois: National Council of Teachers of English.

Giroux, H. A. (1983). Theory and resistance in education: A pedagogy for the opposition. South Hadley, MA: Bergin \& Garvey.

Goffman, E. (1961). Asylums: Essays on social situations of mental patients and other inmates. New York: Anchor.

Haney, W. (1984). Testing reasoning and reasoning about testing. Review of Educational Research, 54 (4), 597-654.

Harste, J. C., Woodward, V. A., \& Burke, C. L. (1984). Language stories and literacy lessons. Portsmouth, NH: Heinemann Educational Books.

Lifford, J., Byron, B., Eckblad, J., \& Ziemian, C. (2000). Reading, responding, reflecting. English Journal, 89 (4), 46-57.

McKay, R \& Kendrick, M. (2001a). Children draw their images of reading and writing. Language Arts, 78 (6), 529-533.

McKay, R. \& Kendrick, M. (2001b). Images of literacy: Young children's drawings about reading and writing. Canadian Journal of Research in Early Childhood Education, 8 (4), 7-22.

McKay, R. \& Kendrick, M. (1999). Young children draw their images of literacy. The Reading Professor, 22 (1), 8-34.

Moll, L. (2000). Inspired by Vygotsky. In Lee, D. \& Smagorinsky, P. (Eds). Vygotskian perspectives on literacy research: Constructing meaning through collaborative inquiry (pp. 256-268). Cambridge, UK: Cambridge University Press.

Newkirk, T. (2000). Misreading masculinity: Speculations on the great gender gap in writing. Language Arts, 77 (4), 294-300.

Nicolopoulou, A., Scales, B., \& Weintraub, J. (1994). Gender differences and symbolic imagination in the stories of four-year-olds. In A. Haas Dyson \& C. Genishi (Eds.), The need for story: Cultural diversity in 
classroom and community (pp.102-123). Urbana, Illinois: National Council of Teachers of English.

O'Brien, D. (1998). Multiple literacies in a high-school program for "at-risk" adolescents. In Alvermann, D., Hinchman, K., Moore, D., Phelps, S, \& Waff, D. (Eds). Reconceptualizing the literacies in adolescents' lives. Mahwah, NJ: Lawrence Erlbaum Associates.

Phelps, S. (1998). Part 1: Adolescents and their multiple literacies. In Alvermann, D., Hinchman, K., Moore, D., Phelps, S, \& Waff, D. (Eds). Reconceptualizing the literacies in adolescents' lives (pp. 1-2). Mahwah, NJ: Lawrence Erlbaum Associates.

Prosser, J. (1998). Image-based research. London: Falmer Press.

Rowe, D. W., \& Harste, J. C. (1986). Metalinguistic awareness in writing and reading: The young child as curricular informant. In D. Yaden \& S. Templeton (Eds.), Metalinguistic awareness and beginning literacy: Conceptualizing what it means to read and write (pp. 235-256). Portsmouth, NH: Heinemann.

Schneider, J. (2001). No blood, guns, or gays allowed!: The silencing of the elementary writer. Language Arts, 78 (5), 415-425.

Solsken, J. W. (1993). Literacy, gender, and work in families and in schools. Norwood, New Jersey: Ablex Publishing Corporation.

Steedman, C. (1982). The tidy house. London: Virago Press Limited.

Street, B. (1995). Social literacies: Critical approaches to literacy development, ethnography, and education. London: Longman.

Vygotsky, L. (1978). Mind in society: The development of higher psychological processes. Cambridge, MA: Harvard University Press.

Weber, S., \& Mitchell C. (2000). That's funny, you don't look like a teacher. London: Falmer Press.

\section{Author Biographies}

Maureen Kendrick teaches in the Department of Language and Literacy Education at the University of British Columbia. Her research focuses on children's multimodal meaning-making in language learning, family and community literacy practices, and the cultural study of children's play.

Email: maureen.kendrick@ubc.ca

Roberta McKay is a Professor in the Department of Elementary Education, Faculty of Education, University of Alberta. Her areas of interest include language and thinking, constructivism, and the role of language in learning. Current research includes children's images of literacy, and constructivist teacher professional development. 